\title{
Wireless Sensor Network(WSN) untuk Predictive Maintenance Lampu Sinyal Kereta Api
}

\section{MUHAMMAD FAUZI NURYASIN, BAMBANG MUKTI WIBAWA, MOHAMMAD TAUFIK}

Departemen Teknik Elektro, Universitas Padjadjaran

Email : muhammad16107@mail.unpad.ac.id

Received 3 Februari 2020 | Revised 1 Maret 2020 | Accepted 11 April 2020

\begin{abstract}
ABSTRAK
Lampu sinyal memiliki peranan yang penting dalam persinyalan kereta api. Pemeliharaan lampu sinyal perlu diperhatikan agar kondisi lampu sinyal tetap sesuai standar. Penelitian ini merancang Wireless Sensor Network (WSN) untuk mengakuisisi parameter lampu sinyal agar dapat dipantau, dianalisis, dan disimpan. Parameter yang diakuisisi berdasarkan dari standar peraturan Menteri Perhubungan Indonesia mengenai lampu sinyal kereta api antara lain intensitas cahaya, tegangan, suhu, dan kelembapan lingkungan lampu sinyal. Sistem tersusun dari tiga subsistem, yaitu sensor node, gateway, dan server. Sistem dapat melakukan pemantauan intensitas lampu sinyal, suhu dan kelembapan lingkungan lampu sinyal, serta tegangan lampu sinyal yang dikirim secara nirkabel yang dapat mencapai jarak hingga 200 m memanfaatkan spektrum radio frekuensi 433 Mhz. Pada saat ada gangguan terhadap lampu sinyal, sistem telah mampu melakukan predictive maintenance berdasarkan standarisasi lampu sinyal.
\end{abstract}

Kata kunci: lampu sinyal, sensor node, gateway, server, wireless sensor network

ABSTRACT

Signal lights has an important role in railway signaling. Proper maintenance must be taken to maintain signal lights so that signal lights condition remain in accordance with the standard. This study designed the Wireless Sensor Network (WSN) to acquire signal lights parameter information so that it can be monitored, analyzed and stored. The parameters acquired are based on the Indonesian Minister of Transportation's regulatory standards regarding railway signal lights such as light intensity, voltage, temperature, and humidity of signal lights. System consists of three subsystems, namely sensor node, gateway, and server. System can monitor signal lights intensity, ambient temperature, ambient humidity, and voltage of signal lights then send those parameters which can reach distances of up to $200 \mathrm{~m}$ utilizing the radio frequency spectrum $433 \mathrm{Mhz}$. When there are interferences with signal lights, system has been able to perform predictive maintenance based on the signal lights standardization.

Keywords. signal lights, sensor node, gateway, server, wireless sensor network 
Wireless Sensor Network (WSN) untuk Pemantauan dan Predictive Maintenance Lampu Sinyal Kereta Api

\section{PENDAHULUAN}

Salah satu transportasi yang umum digunakan di Indonesia adalah kereta api. Berdasarkan informasi Badan Pusat Statistik (Badan Pusat Statistika, 2019) bahwa jumlah penumpang rata-rata kereta api di Indonesia pada tahun 2008 sebanyak 16.173 orang sedangkan tahun 2018 mencapai 32.014 orang. Maka, jumlah penumpang kereta api terjadi peningkatan yang cukup signifikan hingga 97,95\% selama satu dekade. Melihat hal ini, keselamatan transportasi kereta api sangat perlu diperhatikan. Salah satunya sinyal untuk masinis menjalankan kereta api yang diberikan oleh lampu sinyal. Pada persinyalan kereta api terdapat suatu sistem yang dinamakan sistem interlocking sebagai salah satu bagian penting dalam keselamatan transportasi kereta api (Busard, dkk, 2015). Sistem interlocking merupakan sistem yang mengatur pergerakan kereta api dimana memiliki empat komponen yaitu blok, wesel, jalur, dan sinyal. Pada komponen sinyal terdapat lampu sinyal sebagai keputusan terakhir dari sistem interlocking. Lampu sinyal berperan penting dalam sistem interlocking kereta api karena berfungsi sebagai panduan untuk masinis dalam menjalankan kereta api. Lampu sinyal dapat mengalami penurunan kemampuan operasi, gangguan operasi, hingga kerusakan maka dari itu seperti pada alat lainnya, perlu dilakukan pemantauan, pemeliharaan, atau bahkan pergantian. Salah satu teknik pemeliharaan suatu alat adalah predictive maintenance (Selcuk, 2016). Predictive maintenance yaitu teknik pemeliharaan dengan melihat yang membuat sistem tersebut memburuk sehingga dapat segera dilakukan upaya pemeliharaan dengan cara mengevaluasi keadaan sistem dengan melihat informasi-informasi sistem yang telah dipantau dan tersimpan sebelumnya.

Salah satu metode atau teknik yang penulis coba terapkan untuk pemantauan dan predictive maintenance lampu sinyal adalah memanfaatkan Wireless Sensor Network (WSN). Pada saat ini, penelitian Wireless Sensor Network (WSN) telah banyak diterapkan namun cakupannya masih berkonsentrasi dengan desain dan komputasi serta efisiensi algoritma dan protokol sedangkan aplikasinya masih belum terlalu banyak diterapkan (Labrador \& Wightman, 2009). Salah satu diantaranya, (Chen \& Rowe, 2011) mengembangkan algoritima untuk Cable Mode Transition pada Wireless Sensor Network (WSN) yang dapat menentukan minimal jumlah sensor aktif untuk mempertahankan cakupan suatu medan dan konektivitas jaringan WSN. (Cheng, dkk, 2011) mengembangkan pengumpulan data yang dapat menyadari suatu keterlambatan struktur jaringan pada jaringan sensor nirkabel pada Wireless Sensor Network (WSN). (Paul \& Matin, 2011) mengusulkan solusi geometris untuk mencari penempatan yang optimal bagi WSN agar jaringan WSN dapat digunakan pada waktu yang lama. Sedangkan penerapan yang dilakukan untuk lampu seperti oleh (Ekene, dkk, 2013) merancang sistem yang dapat mendiagnosis mandiri terhadap gangguan yang terjadi pada lampu lalu lintas. Penerapan WSN yang termasuk telemonitoring memiliki keunggulan diantaranya fleksibel dan efektif dalam segi harga dan pembiayaan (Rotariu, dkk, 2015).

Berdasarkan permasalahan tersebut maka pada penelitian ini dirancang sebuah sistem yang dapat melakukan pemantauan dan predictive maintenance lampu sinyal pada persinyalan kereta api berbasis mikrokontroler. Sistem dirancang memanfaatkan komponen utama seperti beberapa sensor untuk akuisisi parameter, LoRa dan SIM800L V2 untuk komunikasi, memori penyimpanan untuk menyimpan parameter, aplikasi untuk menampilkan parameter, dan mikrokontroler sebagai otak dari sistem. Sistem dapat menyediakan informasi yang berkaitan dengan performa lampu sinyal serta memberikan notifikasi agar dilakukan investigasi lebih lanjut oleh operator lampu sinyal. Acuan dalam pemberian notifikasi gangguan sesuai dengan peraturan Menteri Perhubungan No 44 Tahun 2018 (Kementerian Perhubungan Republik Indonesia, 2018) tentang "Persyaratan Teknis Peralatan Persinyalan Kereta". 


\section{METODOLOGI}

\subsection{Tahap Penelitian}

Pada penelitian ini metode yang digunakan adalah eksperimental kuantitatif. Penelitian ini menggunakan teknik integrasi rancang bangun alat untuk mengintegrasikan rancang subsistem yang terbagi menjadi tiga, yaitu sensor node, gateway dan server. Tahap penelitian ditunjukkan oleh Gambar 1.

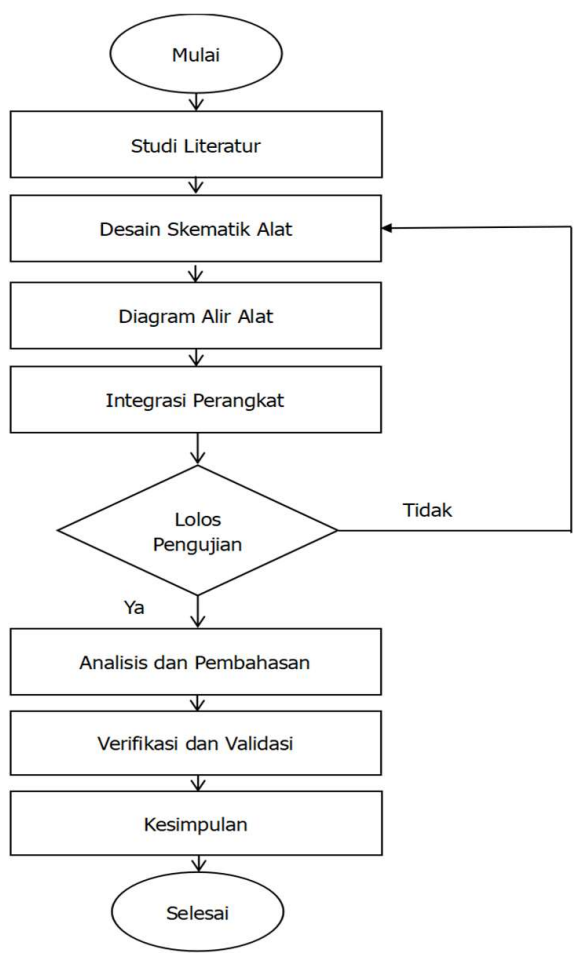

Gambar 1. Diagram Alir Penelitian

\subsection{Perancangan Sistem}

Pada penelitian ini, penulis merancang dua perangkat keras dan satu perangkat lunak yang menyusun suatu sistem Wireless Sensor Network untuk pemantauan dan predictive maintenance lampu sinyal pada persinyalan kereta api kali ini. Kedua perangkat keras tersebut adalah sensor node dan gateway. Pada bagian sensor node terdapat mikrokontroler RobotDyn Mega 2560 Pro Mini yang menjadi mikrokontroler utama atau otak dari perangkat keras sensor node, Sensor suhu dan kelembapan DHT22 sebagai alat pemantauan parameter suhu dan kelembapan lingkungan di sekitar lampu sinyal ketika beroperasi, Sensor cahaya GY-302 BH1750 untuk pemantauan cahaya yang dipancarkan lampu sinyal ketika beroperasi, Konektor sebagai penghubung pembacaan tegangan LED lampu sinyal, Resistor sebagai pembagi tegangan antara LED lampu sinyal dengan mikrokontroler, Modul Micro SD sebagai media penyimpanan parameter yang terekam, Real Time Clock(RTC) sebagai pewaktuan digital pada perangkat keras sensor node, LoRa-02 SX1278 sebagai piranti komunikasi nirkabel antara sensor node dan gateway, dan SIM800L V2 sebagai piranti komunikasi pemberian peringatan antara sistem kepada useratau petugas. Parameter yang terbaca oleh sensor akan diolah oleh mikrokontroler untuk disimpan di memori micro SD dan juga dikirimkan ke gateway melalui LoRa-02 SX1278 dengan memanfaatkan spektrum radio frekuensi 433 Mhz. Mikrokontroler melalui SIM800L V2 mengirimkan notifikasi kepada user atau petugas ketika keadaan lampu sinyal tidak sesuai standar. 
Wireless Sensor Network (WSN) untuk Pemantauan dan Predictive Maintenance Lampu Sinyal Kereta Api

Adapun alur kerja pada subsistem sensor node ke gateway ditunjukkan oleh Gambar 2.

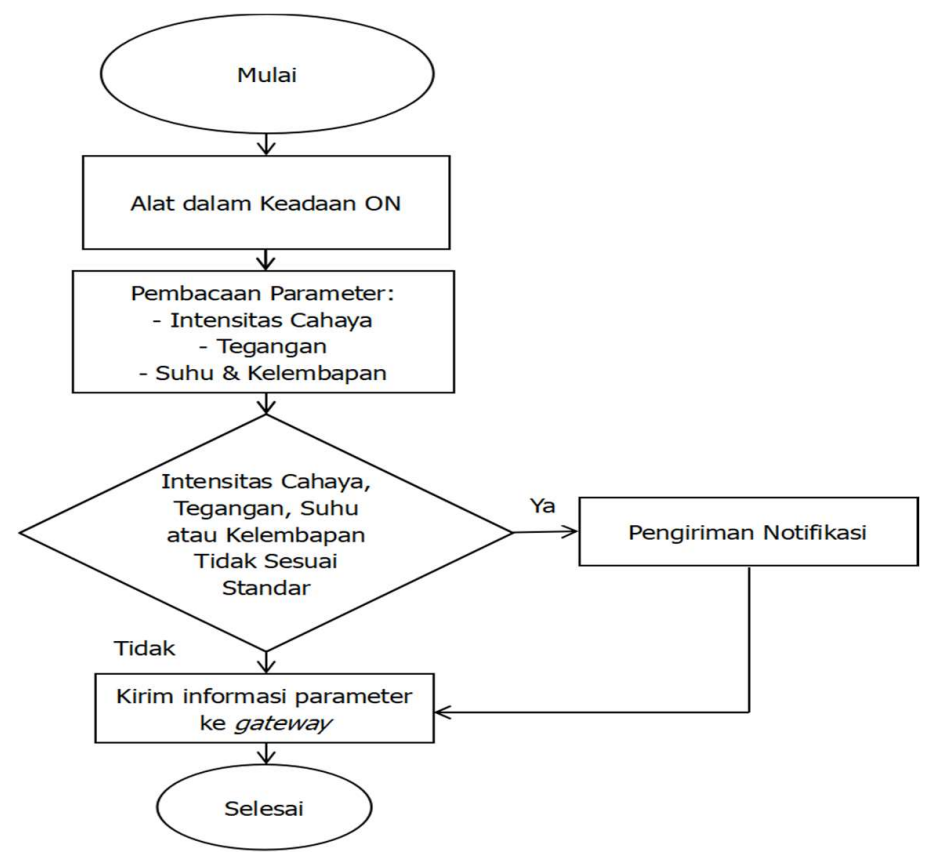

Gambar 2. Alur Kerja Sensor Node - Gateway

Pada bagian gateway terdiri dari RobotDyn Nano V3 sebagai mikrokontroler dan otak dari gateway, dan LoRa-02 SX1278 sebagai piranti komunikasi nirkabel antara sensor node dan gateway. Gatewayberguna dalam menerima informasi parameter yang dikirimkan sensor node melalui LoRa-02 SX1278 yang akan disampaikan gateway ke server. Terakhir, pada server terdapat perangkat lunak aplikasi sebagai sarana pemantauan kondisi lampu sinyal secara real time dan menyimpannya di lokal database yang penulis buat melalui aplikasi Microsoft Visual Studio 2017. Pada server, user dapat melakukan pemantauan real time dan tersimpan secara otomatis di lokal database. Alur kerja gateway ke server ditunjukkan oleh Gambar 3.

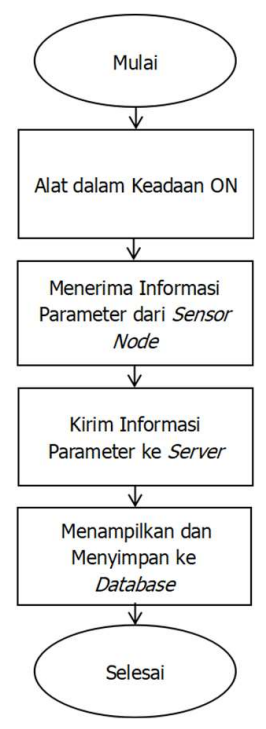

Gambar 3. Alur Kerja Gateway - Server 


\subsection{Desain Sistem}

Pada penelitian ini sistem yang direncanakan tersusun dari gabungan subsistem perangkat keras dan perangkat lunak. Perangkat keras secara garis besar terdiri dari dua bagian yaitu sensor node dan gateway sedangkan perangkat lunak yang dibuat adalah aplikasi sekaligus server predictive maintenance. Setiap subsistem memiliki fungsi yang berbeda tetapi memiliki peran yang sama penting dalam menjalankan kerja sistem. Kombinasi kedua perangkat keras dan lunak ini menghasilkan sistem pemantauan dan predictive maintenance lampu sinyal. Blok diagram sistem ditunjukkan pada Gambar 4.

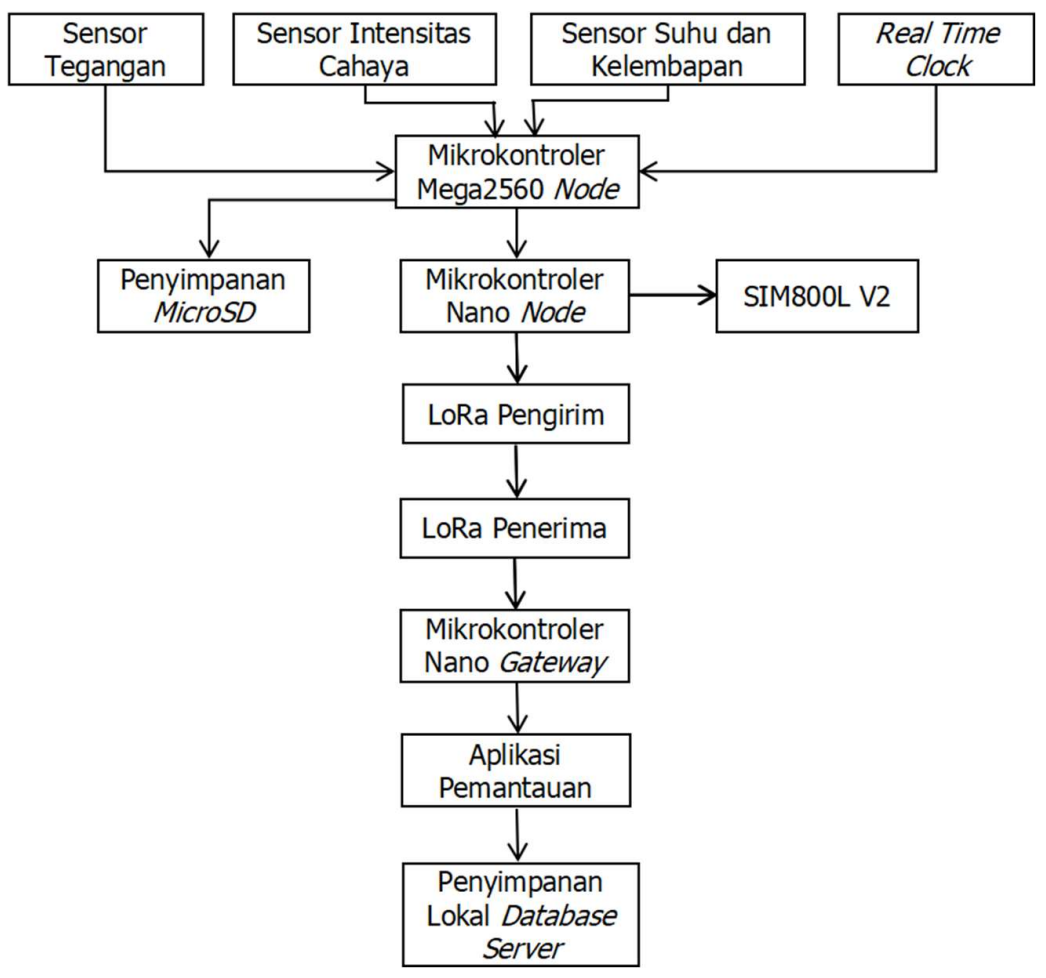

Gambar 4. Blok Diagram Sistem

Pada blok diagram sistem, penulis mencoba menerangkan alur kerja dari gabungan semua subsistem menjadi satu kesatuan sistem. Pertama, sensor tegangan, intensitas cahaya, suhu, dan kelembapan sebagai bagian untuk akuisisi nilai parameter lampu sinyal, lalu real time clock untuk memastikan waktu ketika akuisisi dilakukan. Seluruh nilai parameter digabungkan dan diolah di Mega2560 sensor node untuk disimpan di MicroSD dan dikirimkan secara serial ke mikrokontroler Nano sensor node. Pada Nano, sensor node melakukan evaluasi berdasarkan standarisasi sebagai acuan untuk mengirimkan notifikasi peringatan ke operator lampu sinyal secara nirkabel melalui SIM800L V2. Selain dievaluasi, nilai parameter dikirim ke gateway secara nirkabel melalui LoRa pengirim. LoRa penerima dari gatewayakan menerima informasi parameter dan melanjutkannya ke aplikasi pemantauan yang ada pada komputer atau laptop melalui komunikasi serial, yaitu Universal Serial Bus (USB) antara komputer dengan mikrokontroler Nano gateway. Aplikasi pemantauan akan menampilkan nilai parameter serta grafik perubahan nilainya setiap menit. Nilai parameter akan tersimpan otomatis ke penyimpanan lokal database yang ada pada komputer atau laptop yang dipakai untuk sistem ini. Ilustrasi sistem pada penelitian ini ditunjukkan oleh Gambar 5. Penelitian ini menggunakan perangkat lunak bebas akses seperti KiCad untuk pembuatan skematik rangkaian serta desain PCB untuk sensor node dan gateway. 


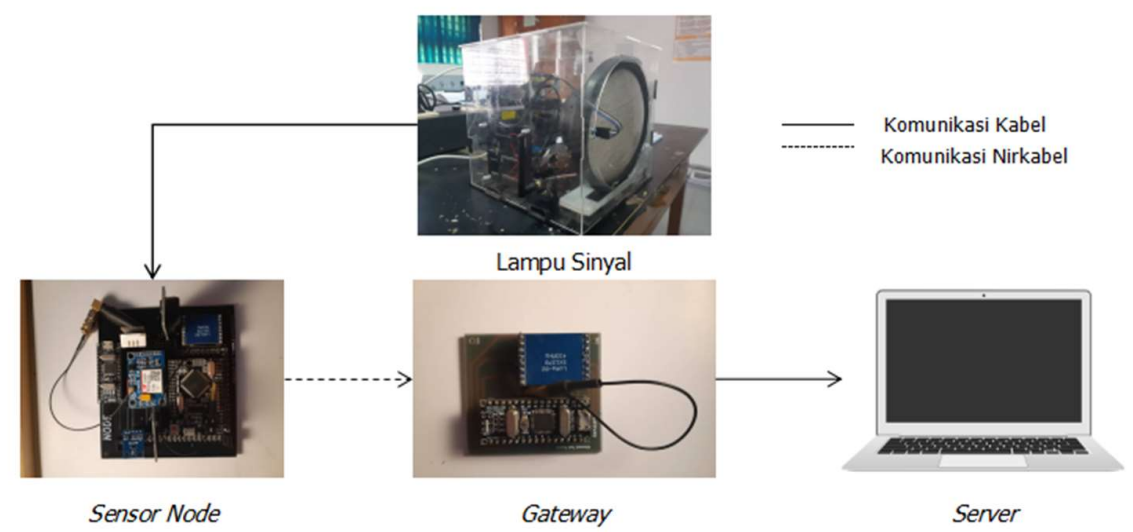

Gambar 5. Ilustrasi Sistem

Visual Studio 2019 Community untuk pembuatan perangkat lunak server dan Arduino IDE untuk pemrograman mikrokontroler. Adapun komponen-komponen yang digunakan pada penelitian ini ditunjukkan pada Tabel 1 . Pemlihan komponen berdasarkan kebutuhan penelitian dan ketersedian komponen yang umum digunakan serta biayanya yang terjangkau.

Tabel 1. Komponen Penyusun Sistem

\begin{tabular}{|c|c|}
\hline Subsistem & Komponen-Komponen Subsistem \\
\hline Sensor Node & $\begin{array}{l}\text { 1. RobotDyn Mega } 2560 \text { Pro Mini dan Nano V3 CH340G (1pcs) } \\
\text { 2. Sensor Suhu dan Kelembapan DHT22 (1pcs) } \\
\text { 3. Konektor IDC ( } 2 \mathrm{pcs}) \\
\text { 4. Resistor ( } 42 \mathrm{pcs}) \\
\text { 5. Modul Micro SD Card (1pcs) } \\
\text { 6. LoRa-02 SX1278 (1pcs) } \\
\text { 7. Real Time Clock (RTC) (1pcs) } \\
\text { 8. Sensor Cahaya GY-302 BH1750 (1pcs) } \\
\text { 9. SIM800L V2.0 (1pcs). }\end{array}$ \\
\hline Gateway & $\begin{array}{l}\text { 1. RobotDyn Nano V3 CH340G (1pcs) } \\
\text { 2. LoRa-02 SX1278 (1pcs) }\end{array}$ \\
\hline Server & $\begin{array}{l}\text { 1. Desktop (1pcs) } \\
\text { 2. Kabel micro USB (1pcs) }\end{array}$ \\
\hline
\end{tabular}

\subsection{Konstruksi Sensor Node}

Perangkat keras sensor node sebagai perangkat yang bertanggung jawab dalam melakukan pengukuran, perekaman, akuisisi, pemrosesan, penyimpanan, dan pengiriman data menuju gateway. Perangkat sensor node yang telah dibangun ditunjukkan oleh Gambar 6 sebagaimana hasil implementasi desain yang telah dibangun. Pada sensor node, mikrokontroler yang digunakan adalah Robotdyn Mega 2560 Pro Mini dan Robotdyn Nano V3 CH340 dengan supply daya yang digunakan melalui tegangan DC 9V. Kedua mikrokontroler ini memiliki peran yang berbeda dalam sensor node dimana Mega 2560 terhubung dengan sensor-sensor yang digunakan antara lain sensor suhu, kelembapan, cahaya, dan tegangan yang tugas utamanya adalah melakukan pengukuran dan perekaman parameter terkait yang selanjutnya dikirimkan melalui komunikasi serial ke mikrokontroler Nano. Pada Nano, dilakukan penerimaan dan pembacaan parameter dari Mega 2560 untuk selanjutnya dievaluasi kecocokan antara nilai parameter dan standar yang telah ditentukan. Nilai kecocokan ini menjadi acuan Nano untuk mengirimkan notifikasi peringatan melalui komunikasi nirkabel 
SIM800L V2 ke operator lampu sinyal sebagai pertimbangan pelaksanaan pemeliharaan. Selain itu, Nano mengirimkan informasi yang diterimanya menggunakan LoRa-02 secara nirkabel untuk disampaikan ke gateway. Setelah mikrokontroler, perangkat sensor node memiliki beberapa sensor. Pertama, sensor suhu dan kelembapan DHT22 berkomunikasi melalui Universal Asynchronous Receiver-Transmitter (UART) dengan Mega 2560, selanjutnya sensor cahaya GY-302 berkomunikasi melalui bus Inter-Intergrated Circuit $\left(\mathrm{I}^{2} \mathrm{C}\right)$ dengan Mega 2560, dan sensor tegangan berkomunikasi melalui serial dengan Mega 2560. RTC DS3231 atau real time clock berfungsi sebagai penunjuk waktu pada sensor node serta berkomunikasi melalui bus Inter-Intergrated Circuit $\left(\mathrm{I}^{2} \mathrm{C}\right)$ dengan Mega 2560. Selanjutnya terdapat modul MicroSD Card untuk penyimpanan pembacaan parameter, modul MicroSD Card berkomunikasi melalui Serial Peripheral Interface (SPI) dengan Mega 2560.

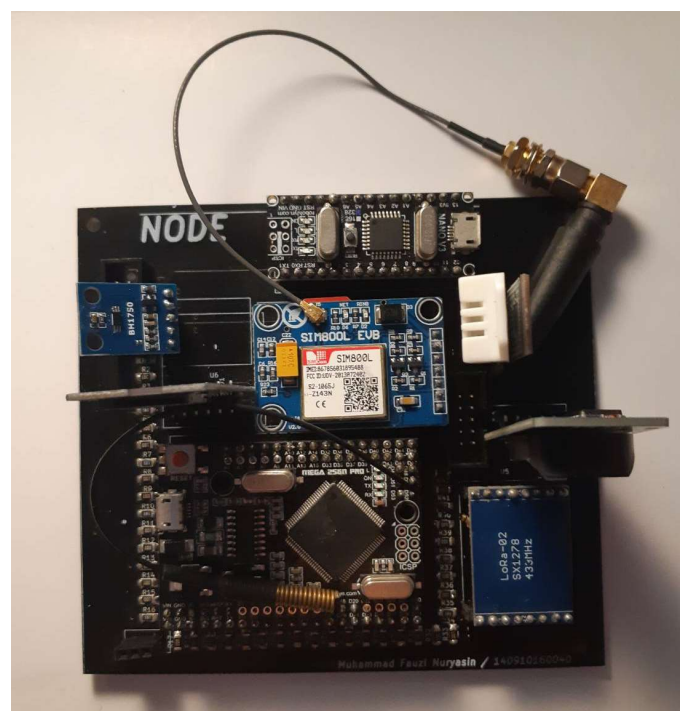

Gambar 6. Sensor Node

Selain komponen-komponen tersebut, terdapat resistor sebagai pembagi tegangan untuk pembacaan tegangan, socket IDC sebagai masukkan tegangan lampu sinyal, dan yang terakhir adalah konektor daya untuk sensor node itu sendiri. Sensor node diposisikan sedemikian rupa di dalam kotak lampu sinyal dengan tujuan agar parameter yang direkam dapat menunjukkan kondisi lampu sinyal tersebut. Posisi peletakkan sensor node seperti pada Gambar 7 yang menunjukkan boks dan pemodelan dari lampu sinyal yang penulis bangun.

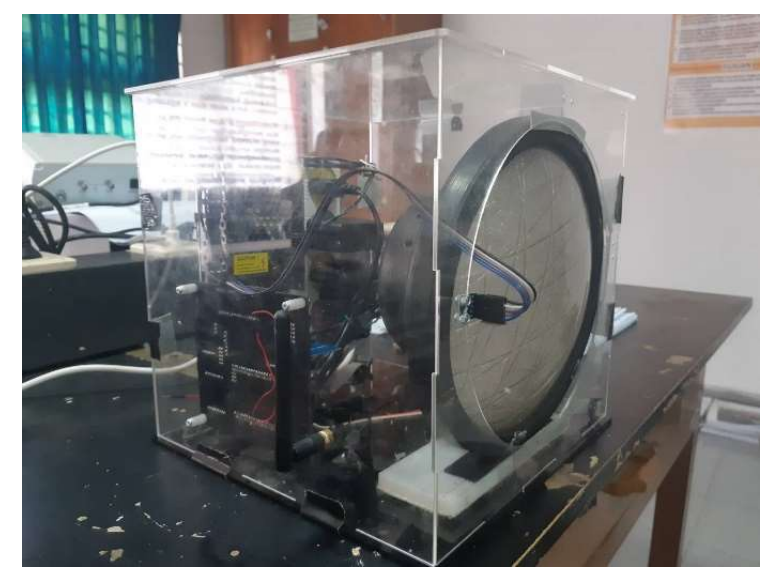

Gambar 7. Pemodelan Lampu Sinyal 


\subsection{Konstruksi Gateway}

Perangkat keras gateway sebagai perangkat yang bertanggung jawab dalam melakukan penerimaan informasi parameter dari sensor node dan mengirimkan informasi tersebut ke perangkat lunak aplikasi sekaligus server. Perangkat gateway yang telah dibangun ditunjukkan oleh Gambar 8 sebagaimana hasil implementasi desain yang dilaksanakan terdiri dari Nano V3 CH340 sebagai mikrokontroler gateway dan LoRa-02 sebagai media komunikasi antara sensor node dan gateway. USB sebagai sumber daya dan komunikasi antara gateway dan perangkat lunak server. Pemilihan LoRa-02 sebagai penerima transmisi informasi parameter berdasarkan ketersediaan komponen dan dapat dikembangkan menjadi banyak sensor node.

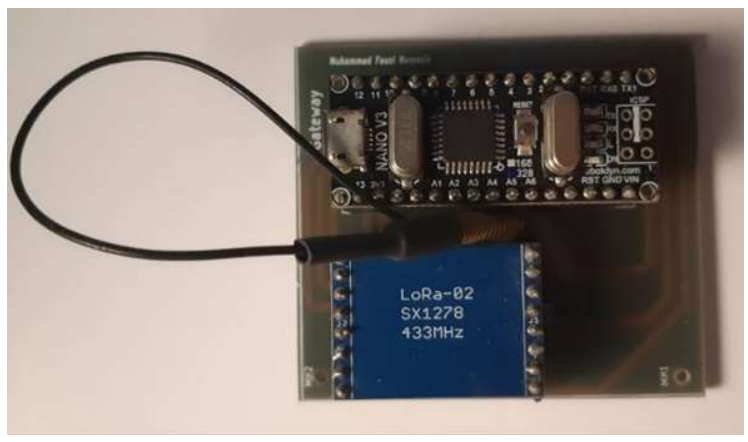

\subsection{Konstruksi Server}

Gambar 8. Gateway

Perangkat lunak serveryang dibangun bertujuan agar informasi parameter yang telah direkam dan dikirim dari sensor node ke gateway pada akhirnya akan sampai ke server. Informasi tersebut akan ditampilkan secara numerik dan grafik. Pada server, informasi parameter yang terekam dapat disimpan di penyimpanan database lokal komputer ataupun laptop memanfaatkan SQL LocalDB. Perangkat lunak server ditunjukkan pada Gambar 9 yang didesain dan dibuat menggunakan aplikasi Visual Studio 2019 Community.

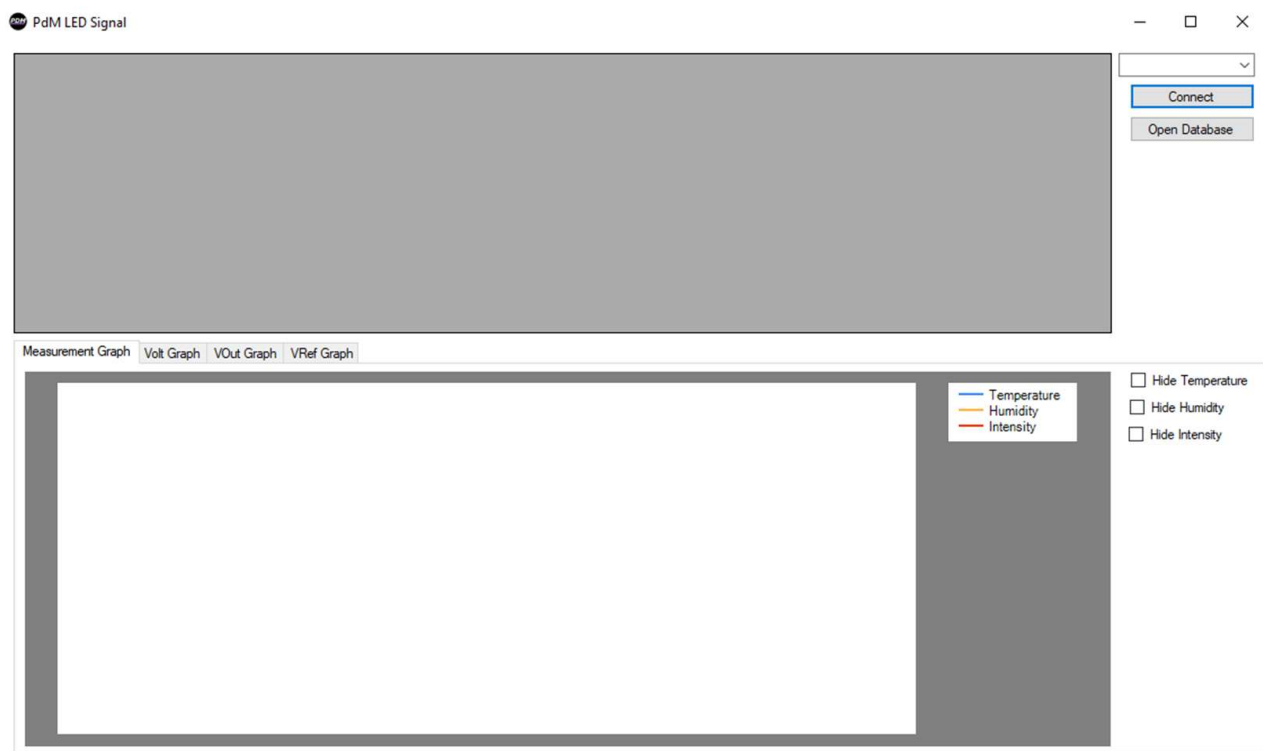

Gambar 9. Tampilan Server 
Nuryasin, dkk

\section{HASIL PENELITIAN DAN PEMBAHASAN}

\subsection{Pengujian Sistem}

Pada pengujian pertama dimana diuji mengenai kemampuan pembacaan suhu dan kelembapan. Pada pengujian ini, dilakukan pengukuran suhu dan kelembapan suatu ruangan dengan selang setiap 15 menit pada setiap pengujiannya. Perbandingan DHT22 dengan alat ukur termohygrometer, yaitu dengan spesifikasi keakurasian pengukuran suhu sebesar $1{ }^{\circ} \mathrm{C}$ dan resolusinya $0,1{ }^{\circ} \mathrm{C}$, sedangkan untuk kelembapannya memiliki akurasi $5 \% \mathrm{RH}$ dan resolusinya $1 \%$. Nilai pengujian didapatkan seperti pada Tabel 2 dengan galat rata-rata dalam 10 pengujian dengan selang 15 menit setiap pengujiannya adalah $4.8 \%$ untuk kelembapan dan $0.82 \%$ untuk suhu yang terukur di suatu ruangan. Dari pengujian ini didapatkan nilai keakurasian untuk suhu sebesar $99.18 \%$ dan kelembapan sebesar 95.2\%. Pada tahap pengujian parameter tegangan dilakukan dengan membandingkan nilai yang terukur pada sensor tegangan yang ada pada subsistem sensor node dengan nilai yang diberikan oleh power supply dimana power supply yang digunakan adalah GWINSTEK GPS-3030DD. Sebelum melakukan pengujian, terlebih dahulu dilakukan kalibrasi dikarenakan tegangan yang terbaca adalah analog sedangkan mikrokontroler Mega 2560 membacanya sebagai 10 bit digitalantara 0 hingga 1023.

Tabel 2. Pengujian Suhu dan Kelembapan Sensor Node

\begin{tabular}{|c|c|c|c|c|c|}
\hline \multicolumn{3}{|c|}{ Kelembapan (\%RH) } & \multicolumn{3}{|c|}{ Suhu $\left({ }^{\circ} \mathrm{C}\right)$} \\
\hline Node (\%RH) & $\begin{array}{c}\text { Alat Ukur } \\
\text { (\%RH) }\end{array}$ & Galat (\%) & Node $\left({ }^{\circ} \mathrm{C}\right)$ & $\begin{array}{c}\text { Alat Ukur } \\
\left({ }^{\circ} \mathrm{C}\right)\end{array}$ & Galat (\%) \\
\hline 52 & 54 & $3.70 \%$ & 25.9 & 26 & $0.38 \%$ \\
\hline 52 & 55 & $5.45 \%$ & 25.8 & 25.8 & $0.00 \%$ \\
\hline 54 & 58 & $6.90 \%$ & 25.8 & 25.7 & $0.39 \%$ \\
\hline 54 & 58 & $6.90 \%$ & 25.3 & 25.6 & $1.17 \%$ \\
\hline 55 & 59 & $6.78 \%$ & 24.8 & 25.3 & $1.98 \%$ \\
\hline 57 & 60 & $5.00 \%$ & 22.8 & 22.7 & $0.44 \%$ \\
\hline 57 & 60 & $5.00 \%$ & 21.5 & 21.3 & $0.94 \%$ \\
\hline 58 & 60 & $3.33 \%$ & 21.2 & 21 & $0.95 \%$ \\
\hline 58 & 60 & $3.33 \%$ & 21 & 20.8 & $0.96 \%$ \\
\hline 60 & 61 & $1.64 \%$ & 20.8 & 20.6 & $0.97 \%$ \\
\hline \multicolumn{2}{|c|}{ Rata-rata } & $4.80 \%$ & \multicolumn{2}{|c|}{ Rata-rata } & $0.82 \%$ \\
\hline
\end{tabular}

Selain itu, nilai tegangan yang diperbolehkan hanyalah dalam rentang 0-5 $\mathrm{V}$ maka dari itu dirancanglah rangkaian pembagi tegangan guna membatasi nilai tegangan yang masuk ke mikrokontroler dengan menggunakan resistor SMD R1 bernilai 20 ohm dan R2 bernilai 180 ohm. Pada program mikrokontroler dilakukan kalibrasi berdasarkan regresi linear sederhana. Nilai pengujian parameter tegangan ditunjukkan pada Grafik 1 memiliki galat rata-rata yaitu perbedaan tegangan terbaca antara sensor node dan power supply sebesar $1.03 \%$. 
Wireless Sensor Network (WSN) untuk Pemantauan dan Predictive Maintenance Lampu Sinyal Kereta Api

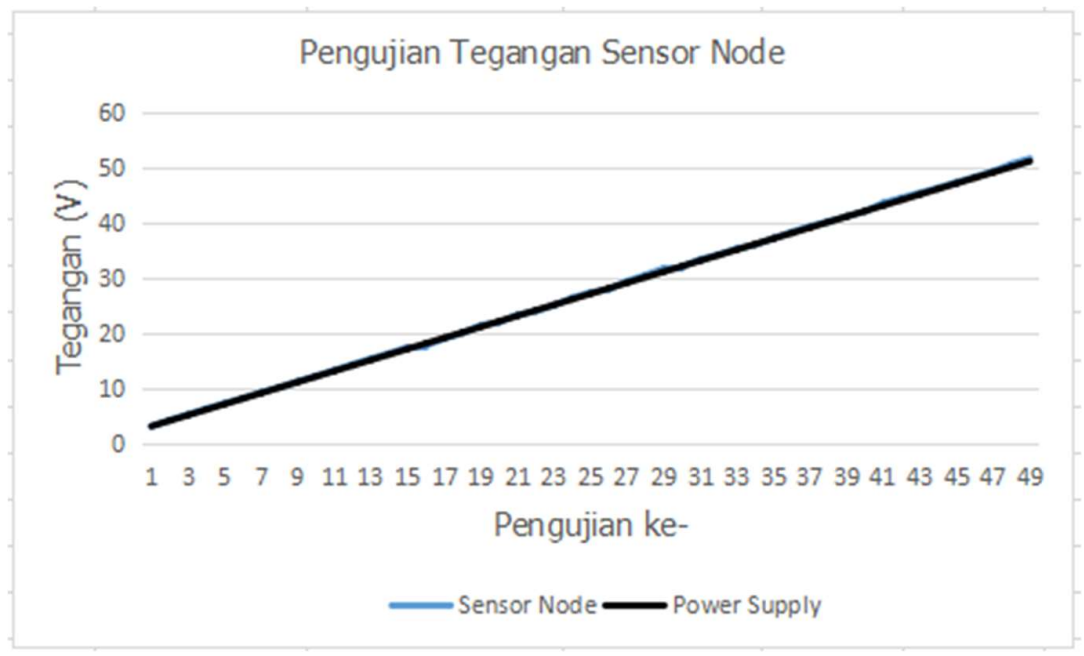

Grafik 10. Pengujian Tegangan Sensor Node

Pada pengujian parameter intenstias cahaya dilakukan dengan membandingkan nilai lux yang didapatkan oleh GY-302 dengan yang didapatkan oleh alat ukur luxmeter dari Lutron dengan jenis LX-1108. Pengujian ini memanfaatkan lampu DC yang kecerahannya diatur melalui Pulse Width Modulation (PWM). Nilai pengujian intensitas cahaya ditunjukkan oleh Tabel 3.

Tabel 3. Pengujian Intensitas Cahaya

\begin{tabular}{|c|c|c|}
\hline Node (lux) & Alat Ukur (lux) & Galat (\%) \\
\hline 1335 & 1370 & $2.55 \%$ \\
\hline 506 & 536 & $5.60 \%$ \\
\hline 242 & 262 & $7.63 \%$ \\
\hline 125 & 130 & $3.85 \%$ \\
\hline 60 & 64 & $6.25 \%$ \\
\hline \multicolumn{2}{|c|}{ Rata-rata } & $5.18 \%$ \\
\hline
\end{tabular}

Selanjutnya pengujian komunikasi dilakukan di jalan lurus dengan hambatan berupa tanjakan dan pepohonan untuk mengetahui apakah komponen LoRa dapat bekerja dan berkomunikasi dengan baik. Hasil pengujian ditunjukkan pada Tabel 4. Nilai RSSI yang didapatkan paling baik ketika jarak pengujian di $10 \mathrm{~m}$ dan ketika jarak pengujian diperjauh. Nilai RSSI memburuk namun tetap terkirim normal hingga pada jarak pengujian terjauh 200 meter. Penulis mencoba pengujian lebih jauh dari $200 \mathrm{~m}$ tapi pesan tidak tertangkap oleh gateway sehingga jarak terjauh komunikasi nirkabel frekuensi $433 \mathrm{MHz}$ menggunakan LoRa-02 pada jarak 200 meter.

Tabel 4. Pengujian Komunikasi

\begin{tabular}{|c|c|c|}
\hline RSSI (dbm) & Jarak (m) & Pesan \\
\hline-40 & 10 & Terkirim \\
\hline-54 & 50 & Terkirim \\
\hline-91 & 100 & Terkirim \\
\hline-110 & 175 & Terkirim \\
\hline-116 & 200 & Terkirim \\
\hline
\end{tabular}


Pada pengujian pemantauan lampu sinyal, informasi parameter yang dikirim sensor node ke gateway akan dilanjutkan ke server melalui komunikasi Universal Serial Bus (USB) ke laptop atau komputer. Server yang digunakan adalah open source dengan memanfaatkan ketersediaan lokal database SQL server dari Microsoft Visual Studio 2019. Selain menjadikan server, dirancang juga aplikasi predictive maintenance melalui Visual Studio 2019. Pada pengujian ini dilakukan pengiriman informasi parameter dari gateway ke server. Aplikasi predictive maintenance juga dapat menampilkan grafik real time perubahan dari setiap informasi parameter yang diterima. Hasil penampilan penyimpanan database lokal server diperlihatkan pada Gambar 11 dan informasi parameter terlihat pada Gambar 12.

\begin{tabular}{|c|c|c|c|c|c|c|c|c|c|c|c|c|c|c|c|c|c|c|}
\hline Id & Date & Temperature & Humidity & Intensity & V1 & V2 & V3 & V4 & V5 & V6 & V7 & V8 & V9 & Vout1 & VOut2 & Vout3 & VRef1 & VRef2 \\
\hline 1 & $10 / 30 / 20199: 20$ & 23.4 & 66.6 & 5 & 11 & 11.15 & 11.7 & 12.36 & 12.16 & 11.91 & 11.85 & 11.6 & 11.75 & 12.86 & 12.71 & 12.51 & 12.81 & 12.46 \\
\hline 2 & $10 / 30 / 20199: 20$ & 23.4 & 66.7 & 5 & 10.95 & 11.15 & 11.7 & 12.36 & 12.16 & 11.91 & 11.85 & 11.55 & 11.75 & 12.86 & 12.71 & 12.51 & 12.81 & 12.46 \\
\hline 3 & 10/30/2019 9:20 & 23.4 & 66.7 & 5 & 10.95 & 11.15 & 11.7 & 12.36 & 12.16 & 11.91 & 11.85 & 11.55 & 11.75 & 12.91 & 12.76 & 12.56 & 12.81 & 12.46 \\
\hline 4 & 10/30/2019 9:20 & 23.4 & 66.7 & 5 & 10.95 & 11.15 & 11.7 & 12.36 & 12.16 & 11.91 & 11.85 & 11.6 & 11.75 & 12.91 & 12.76 & 12.56 & 12.86 & 12.46 \\
\hline 5 & 10/30/2019 9:21 & 23.4 & 66.7 & 5 & 10.95 & 11.15 & 11.7 & 12.36 & 12.16 & 11.96 & 11.85 & 11.55 & 11.75 & 12.91 & 12.76 & 12.56 & 12.86 & 12.36 \\
\hline 6 & 10/30/2019 9:21 & 23.4 & 66.7 & 5 & 10.95 & 11.15 & 11.7 & 12.36 & 12.16 & 11.96 & 11.85 & 11.55 & 11.75 & 12.91 & 12.76 & 12.56 & 12.86 & 12.51 \\
\hline 7 & 10/30/2019 9:21 & 23.4 & 66.9 & 5 & 10.95 & 11.15 & 11.7 & 12.36 & 12.16 & 11.96 & 11.85 & 11.55 & 11.75 & 12.91 & 12.76 & 12.56 & 12.86 & 12.46 \\
\hline 8 & 10/30/2019 9:21 & 23.4 & 66.9 & 5 & 10.9 & 11.15 & 11.7 & 12.36 & 12.16 & 11.91 & 11.85 & 11.55 & 11.75 & 12.91 & 12.76 & 12.56 & 12.86 & 12.46 \\
\hline 9 & 10/30/2019 9:21 & 23.4 & 66.7 & 5 & 10.85 & 11 & 11.6 & 12.21 & 12.01 & 11.8 & 11.7 & 11.4 & 11.6 & 12.76 & 12.61 & 12.46 & 12.71 & 12.31 \\
\hline 10 & 10/30/2019 9:21 & 23.5 & 66.8 & 5.83 & 10.8 & 11 & 11.6 & 12.26 & 12.01 & 11.8 & 11.7 & 11.4 & 11.6 & 12.81 & 12.66 & 12.41 & 12.71 & 12.36 \\
\hline 11 & 10/30/2019 9:21 & 23.5 & 66.6 & 5.83 & 10.8 & 11.05 & 11.6 & 12.26 & 12.06 & 11.8 & 11.75 & 11.45 & 11.65 & 12.81 & 12.66 & 12.46 & 12.76 & 12.36 \\
\hline 12 & 10/30/2019 9:21 & 23.4 & 66.6 & 5.83 & 10.8 & 11.05 & 11.6 & 12.26 & 12.06 & 11.8 & 11.75 & 11.45 & 11.65 & 12.81 & 12.71 & 12.46 & 12.76 & 12.36 \\
\hline 13 & $10 / 30 / 20199: 22$ & 23.5 & 66.7 & 5.83 & 10.8 & 11.05 & 11.6 & 12.26 & 12.06 & 11.8 & 11.75 & 11.45 & 11.65 & 12.81 & 12.66 & 12.46 & 12.76 & 12.36 \\
\hline 14 & 10/30/2019 9:22 & 23.5 & 66.5 & 5.83 & 10.8 & 11.05 & 11.7 & 12.26 & 12.06 & 11.8 & 11.75 & 11.45 & 11.65 & 12.81 & 12.66 & 12.46 & 12.76 & 12.36 \\
\hline 15 & $10 / 30 / 20199: 22$ & 23.5 & 66.6 & 5.83 & 10.8 & 11.05 & 11.6 & 12.26 & 12.01 & 11.8 & 11.75 & 11.45 & 11.65 & 12.81 & 12.66 & 12.46 & 12.76 & 12.36 \\
\hline 16 & $10 / 3$ & 23. & 66. & 5.83 & 10.8 & 11.05 & 11.6 & 12.26 & 12.06 & 11.8 & 11.75 & 11.45 & 11.65 & 12.81 & 12.66 & 12.46 & 12.76 & 12.36 \\
\hline 17 & $10 / 30 / 20199: 22$ & & 66.5 & 5.83 & 10.75 & 11.05 & 11.6 & 12.26 & 12.06 & 11.8 & 11.75 & 11.45 & 11.65 & 12.86 & 12.66 & 12.46 & 12.76 & 12.36 \\
\hline 18 & 0/2019 9:22 & & 66.5 & 5.83 & 10.8 & 11.05 & 11.6 & 12.26 & 12.06 & 11.85 & 11.75 & 11.45 & 11.65 & 12.81 & 12.71 & 12.51 & 12.76 & 12.41 \\
\hline 19 & 10/30/2019 9:22 & 23.5 & 66.4 & 299.17 & 10.75 & 11.05 & 11.6 & 12.31 & 12.06 & 11.85 & 11.75 & 11.45 & 11.65 & 12.86 & 12.71 & 12.51 & 12.76 & 12.41 \\
\hline 20 & 10/30/2019 9:22 & 23.5 & 66.3 & 310.83 & 10.75 & 10.95 & 11.6 & 12.31 & 12.06 & 11.8 & 11.75 & 11.45 & 11.65 & 12.86 & 12.71 & 12.51 & 12.76 & 12.41 \\
\hline 21 & $10 / 30 / 20199: 22$ & 23.5 & 66.4 & 306.67 & 10.75 & 11.05 & 11.6 & 12.26 & 12.06 & 11.85 & 11.75 & 11.45 & 11.65 & 12.86 & 12.71 & 12.51 & 12.81 & 12.41 \\
\hline
\end{tabular}

Gambar 11. Tampilan Database

? PdM LED Signa

\begin{tabular}{|c|c|c|c|c|c|c|c|c|c|c|}
\hline & Date & Temperature & Humidity & Intensty & V1 & V2 & V3 & V4 & v5 & $v_{\wedge} \hat{~}$ \\
\hline \multirow[t]{10}{*}{ - } & 11/11/20199:19. & 23.40 & 66.60 & 5.00 & 11.00 & 11.15 & 11.70 & 12.36 & 12.16 & 11 \\
\hline & 11/11/2019 9:19.. & 23.40 & 66.70 & 5.00 & 10.95 & 11.15 & 11.70 & 12.36 & 12.16 & 11 \\
\hline & 11/11/2019 9:19... & 23.40 & 66.70 & 5.00 & 10.95 & 11.15 & 11.70 & 12.36 & 12.16 & 11 \\
\hline & 11/11/2019 9:19. & 23.40 & 66.70 & 5.00 & 10.95 & 11.15 & 11.70 & 12.36 & 12.16 & 11 \\
\hline & 11/11/2019 9.20... & 23.40 & 66.70 & 5.00 & 10.95 & 11.15 & 11.70 & 12.36 & 12.16 & 11 \\
\hline & 11/11/2019 9:20. & 23.40 & 66.70 & 5.00 & 10.95 & 11.15 & 11.70 & 12.36 & 12.16 & 11 \\
\hline & $11 / 11 / 20199.20 \ldots$ & 23.40 & 66.90 & 5.00 & 10.95 & 11.15 & 11.70 & 12.36 & 12.16 & 11 \\
\hline & 11/11/2019 9:20... & 23.40 & 66.90 & 5.00 & 10.90 & 11.15 & 11.70 & 12.36 & 12.16 & 11 \\
\hline & 11/11/20199:20. & 23.40 & 66.70 & 5.00 & 10.85 & 11.00 & 11.60 & 12.21 & 12.01 & 11 \\
\hline & $11 / 11 / 9 n+00.2 n$ & $m \in n$ & ecen & $=002$ & in on & $11 \mathrm{~mm}$ & $11 \mathrm{~cm}$ & $17 x$ & $13 \mathrm{nt}$ & 112 \\
\hline
\end{tabular}
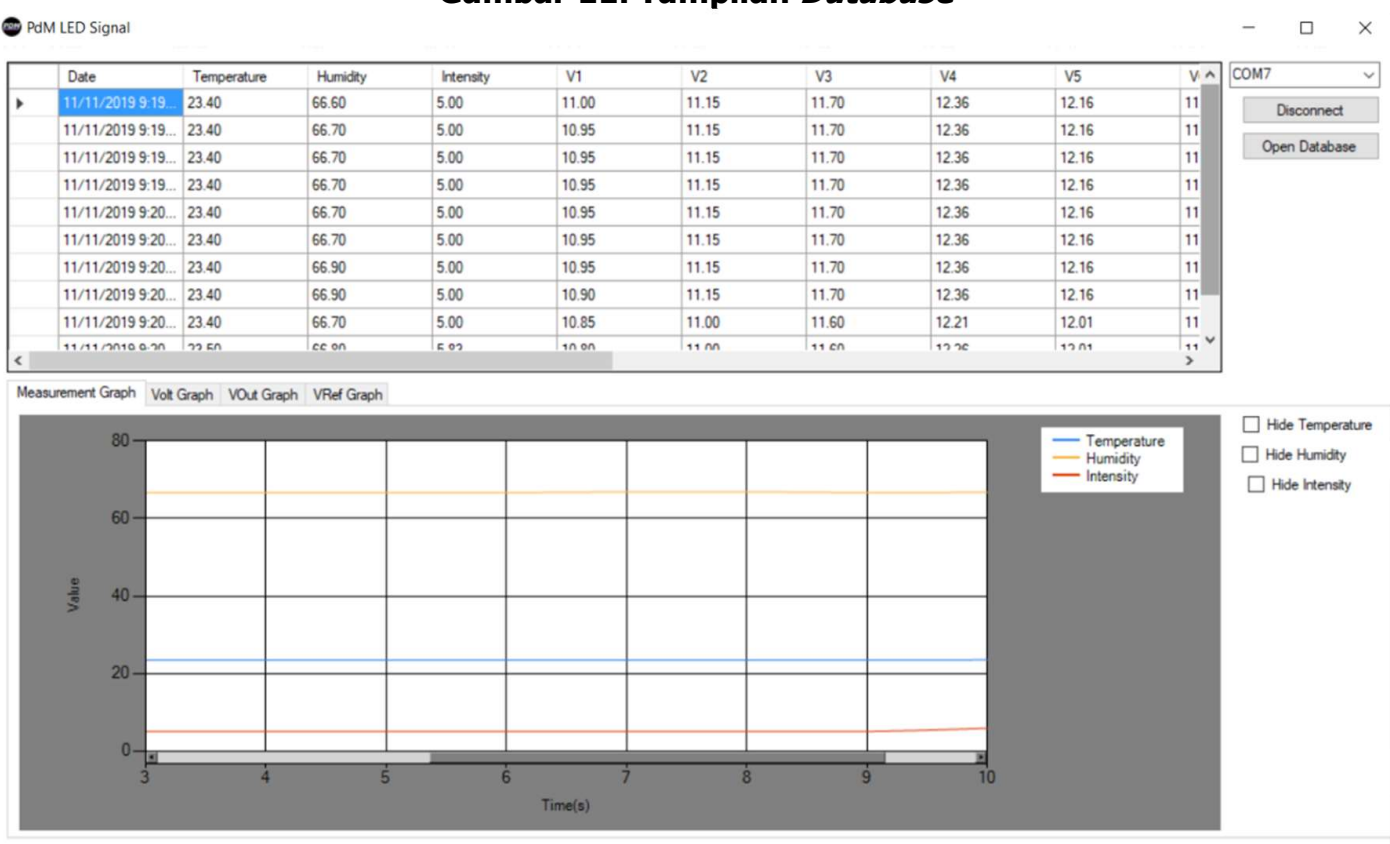
Terakhir, pengujian predictive maintenance dilakukan rekayasa nilai informasi parameter untuk mengetahui respon dari SIM800L V2 sebagai aktuator dalam penelitian ini. Standar yang digunakan berdasarkan peraturan pemerintah mengenai standar lampu sinyal. Nomor seluler yang digunakan oleh operator adalah +6281220696596 , sedangkan nomor yang digunakan SIM800L V2 adalah +6282317178974. Tegangan yang diukur pada lampu sinyal merupakan tegangan sensing dan regulator yang pada umumnya berada pada 12 VDC dengan akurasi +$5 \%$ VDC sehingga penulis menentukan batas toleransi berada di kurang dari 11.4 VDC atau lebih dari 12.6 VDC. Peraturan mengklaim bahwa jarak pandang lampu sinyal sejauh $600 \mathrm{~m}$. Pada prototipe penelitian ini, sensor cahaya mendapatkan intensitas lampu sinyal pada keadaan normal rata-rata dari 100 kali sampling sebesar 256.632 lux. Penulis menentukan bahwa toleransi mendapatkan jarak pandang $600 \mathrm{~m}$ maka lux yang minimal ditangkap sensor adalah $60 \%$ dari performa kondisi idealnya, yaitu sebesar 153.979 lux.

Tabel 5. Pengujian Predictive Maintenance

\begin{tabular}{|c|c|}
\hline Pengujian & Hasil \\
\hline Suhu $>45^{\circ} \mathrm{C}$ & $\begin{array}{c}\text { SIM800L V2 mengirim pesan "Parameter } \\
\text { suhu tidak sesuai standar!" }\end{array}$ \\
\hline Kelembapan $>90 \% \mathrm{RH}$ & $\begin{array}{c}\text { SIM800L V2 mengirim pesan "Parameter } \\
\text { kelembapan tidak sesuai standar!" }\end{array}$ \\
\hline Tegangan $>12.6 \mathrm{~V}$ & $\begin{array}{c}\text { SIM800L V2 mengirim pesan "Parameter } \\
\text { tegangan ada yang tidak sesuai standar!" }\end{array}$ \\
\hline Tegangan $<11.4 \mathrm{~V}$ & $\begin{array}{c}\text { SIM800L V2 mengirim pesan "Parameter } \\
\text { tegangan ada yang tidak sesuai standar!" }\end{array}$ \\
\hline 50 lux $<$ Intensitas $<153.979$ lux & $\begin{array}{c}\text { SIM800L V2 mengirim pesan "Parameter } \\
\text { intensitas tidak sesuai standar!" }\end{array}$ \\
\hline $\begin{array}{c}\text { Suhu }>45^{\circ} \mathrm{C} \& \& \text { Kelembapan }>90 \% \\
\text { RH \&\& Tegangan LED }>12.6 \text { V \& } \\
\text { Tegangan }<11.4 \mathrm{~V} \& \& 50 \text { lux }< \\
\text { Intensitas }<153.979 \text { lux }\end{array}$ & $\begin{array}{c}\text { SIM800L V2 mengirim pesan "Seluruh } \\
\text { parameter tidak sesuai standar!" }\end{array}$ \\
\hline
\end{tabular}

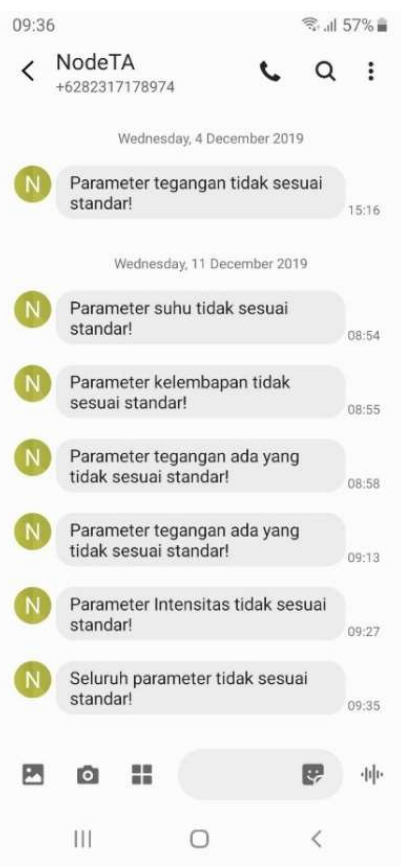

Gambar 13. Pengiriman Notifikasi Gangguan 
Rekayasa pertama dilakukan dengan dikondisikan suhu ruangan sesungguhnya hingga melebihi batas standar kerja sebesar $45^{\circ} \mathrm{C}$ dimana sistem tetap dapat mengirimkan notifikasi peringatan. Selanjutnya, rekayasa kedua dengan dikondisikan kelembapan ruangan sesungguhnya hingga lebih dari 95\% RH dimana dalam kondisi pengujian, sistem dapat mengirimkan notifikasi peringatan. Ketiga, sistem diberi tegangan lebih dari $12.6 \mathrm{~V}$, setelah itu tegangan kurang dari $11.4 \mathrm{~V}$ dimana sistem masih dapat mengirimkan notifikasi peringatan. Selain itu, sistem dikondisikan agar menangkap intensitas turun kurang dari 153.979 lux namun tetap lebih dari 50 lux dari intensitas cahaya lingkungan yang ditangkap sensor sebagai threshold walaupun dari 20 kali sampling didapatkan rata-rata intensitas lingkungan yang tertangkap sebesar 23.818 lux. Penentuan threshold ini karena berkaitan dengan penggunaan lampu sinyal yang tidak selalu dalam keadaan menyala dan hasil didapatkan bahwa sistem masih dapat mengirimkan notifikasi peringatan. Terakhir dengan membuat seluruh parameter tidak sesuai standar dimana didapatkan sistem mengirimkan notifikasi peringatan. Hasil pengujian predictive maintenance ditunjukkan pada Tabel 5, ketika nilai parameter tidak sesuai dengan standar peraturan, maka SIM800L V2 segera melakukan notifikasi peringatan ke operator. Sistem melakukan perekaman, pengujian, dan evaluasi nilai parameter setiap satu menit. Hasil pengiriman Short Message Service (SMS) ditunjukkan oleh Gambar 13.

\section{KESIMPULAN}

Penerapan Wireless Sensor Network (WSN) untuk pemantauan dan predictive maintenance lampu sinyal persinyalan kereta api berbasis mikrokontroler telah diimplementasikan berdasarkan standarisasi yang ditunjukkan oleh pengiriman notifikasi peringatan parameter yang tidak sesuai standar peraturan yang berlaku ke nomor seluler operator lampu sinyal. Pembuatan database dan prototipe sistem telah berhasil dilakukan dimana informasi parameter telah dapat direkam, disajikan, ditampilkan, dan disimpan. Pada penelitian ini dari hasil pengujian didapatkan galat pengukuran suhu sebesar $0.82 \%$, galat pengukuran kelembapan sebesar $4.80 \%$, galat pengukuran intensitas cahaya sebesar $5.18 \%$, dan galat pengukuran tegangan sebesar $1.03 \%$. Pengiriman informasi parameter terjauh yang dapat ditangkap dan ditampilkan sistem, yakni sejauh 200 meter. Pada implementasi dalam kondisi sesungguhnya, penulis menyarankan untuk meletakan sensor node di dalam boks yang menyatu dengan lampu sinyal agar akuisisi parameter oleh sensor node sesuai dengan kondisi sesungguhnya yang terjadi pada lampu sinyal. Terakhir, peletakan gateway dapat disesuaikan dengan tempat petugas yang bertanggung jawab terhadap lampu sinyal agar mudah diakses dengan kentuan dimana jarak gateway tidak lebih jauh dari 200 meter terhadap sensor node.

\section{DAFTAR RUJUKAN}

Badan Pusat Statistika. (2019, Januari 19). Jumlah Penumpang Kereta Api. Diakses dari https://www.bps.go.id/linkTableDinamis/view/id/815.

Busard, S., Cappart, Q., Limbrée, C., Pecheur, C., \& Schaus, P. (2015). Verification of railway interlocking systems. Electronic Proceedings In Theoretical Computer Science, (pp. 1931).

Chen, X., \& Rowe, N. (2011). An Energy-Efficient Communication Scheme in Wireless Cable Sensor Networks. 2011 IEEE International Conference On Communications (ICC), (pp. 1-5). 
Cheng, C., Tse, C., \& Lau, F. (2011). A Delay-Aware Data Collection Network Structure for Wireless Sensor Networks. IEEE Sensors Journal, 11(3), 699-710.

Ekene, S., Micheal, C., Kennedy, C., \& Genevra, E. (2013). Self diagnostic system for Predictive Maintenance of traffic light control system. 2013 IEEE International Conference on Emerging \& Sustainable Technologies for Power \& ICT in a Developing Society (NIGERCON), (pp 308-313).

Kementerian Perhubungan Republik Indonesia. (2018, April 12). Persyaratan Teknis Peralatan Persinyalan Kereta Api. Diakses dari http://jdih.dephub.go.id/produk hukum/view/VUUwZ05EUWdWRUZJVIU0Z01qQXhPQT09

Labrador, M., \& Wightman, P. (2009). Topology Control in Wireless Sensor Networks. Springer Science \& Business Media.

Paul, B., \& Matin, M. (2011). Optimal geometrical sink location estimation for two-tiered wireless sensor networks. IET Wireless Sensor Systems, 74-84.

Rotariu, C., Bozomitu, R., Cehan, V., Pasarica, A., \& Costin, H. (2015). A wireless sensor network for remote monitoring of bioimpedance. 2015 38th International Spring Seminar On Electronics Technology (ISSE), (pp. 487-490).

Selcuk, S. (2016). Predictive maintenance, its implementation and latest trends. Proceedings Of The Institution Of Mechanical Engineers, Part B: Journal Of Engineering Manufacture, 231(9), 1670-1679. 